\title{
Influence Analysis of Composite Action of Floor Slab on Aseismic Behavior of Mixed Frame Structures
}

\author{
Yang-Bing LIU ${ }^{1, a,{ }^{*}}$, Tian-Feng $\mathrm{CAO}^{2, \mathrm{~b}}$ \\ ${ }^{1}$ College of civil engineering, Nanyang Institute of Technology, Nanyang City Henan Prov. 473004, \\ China \\ ${ }^{2}$ College of civil engineering, Chongqing University, Chongqing 400045, China \\ aybliu1123@sohu.com, bfatfatbeat@gmail.com \\ ${ }^{*}$ Corresponding author
}

\begin{abstract}
Keywords: Composite Action of Floor Slab, Mixed Frame, Composite Beam, Concrete-filled Square Steel Tubular Column, Aseismic Behavior.
\end{abstract}

\begin{abstract}
To study the influence of composite action of floor slab on aseismic behavior of steel-concrete mixed frame structures, models of composite beam-concrete-filled square steel tubular columns frame structure (CB-CFST) and steel beam- concrete-filled square steel tubular columns frame structure (SB-CFST) with and without considering the composite action of floor slab were constructed. Influence analysis of elastic and inelastic aseismic behavior was conducted. The influence of the composite action of floor slab on mechanical behavior, deformation and damage state of structures were investigated. The results showed that the upper column design internal force of steel beam frames would be smaller than that of composite beam frames, which would make the structure design unsafe. And considering the composite action of floor slab, the displacement response of CB-CFST was smaller than that of SB-CFST in the mass. Furthermore, real damage state couldn't be reflected without considering the composite action of floor slab.
\end{abstract}

\section{Introduction}

As the most simple and basic structural system, the frame system has the characteristics of simple design and clear transmission force. The mixed frame consists of composite columns and steel beams or composite beams. With its good economy and excellent seismic performance, the steel-concrete mixed frame has been widely used in multi-storey and high-rise buildings. For the composite beam frames under the horizontal load, the composite action between steel beams and concrete floor slab was always ignored, and composite beams was only designed as steel beams, which was unreasonable during the structural elastic analysis[1]. Furthermore whether the composite action would affect the deformation and failure state under strong earthquake is also a problem to discuss. And up to now, the available research about this aspect is not much [2].

In this paper, the elastic models and inelastic models of the two 15-storeyed mixed frames were constructed. According to the actual situation, the CB-CFST frame was used to consider the composite action of floor slab, and SB-CFST frame was used not to consider the composite action. By using SAP2000 software, the mode analysis, the response spectrum analysis, the elastic and the inelastic dynamic time history analysis for the two structures were performed. By comparing the analysis results, the influence of the composite action of floor slab on mechanical behavior, deformation and damage state of structures were investigated.

\section{Structural Model}

The layout of the plane and elevation was illustrated in Fig. 1. For the two buildings, the bottom storey height is $4.5 \mathrm{~m}$, the other storey height was $3.6 \mathrm{~m}$, and the total height was $54.9 \mathrm{~m}$. In Fig. 1, "Z" denoted columns and "L" denoted beams. The sections and dimensions of the frame columns and beams were shown in Fig. 2. Frame elements were used to simulate columns and beams. The CFST columns concrete strength was C40, and the steel tube used Q345 steel. The steel beam used Q235-B 
steel. The floor and the roof used $140 \mathrm{~mm}$ thick C30 RC slab simulated by shell elements, the reinforcement strength in which was HRB335. The diameter of the upper reinforcement in concrete slab was $14 \mathrm{~mm}$, and the diameter of headed stub was $19 \mathrm{~mm}$. The nominal values of dead load and live load on slabs were respectively $4.5 \mathrm{kN} / \mathrm{m}^{2}$ and $2.0 \mathrm{kN} / \mathrm{m}^{2}$.

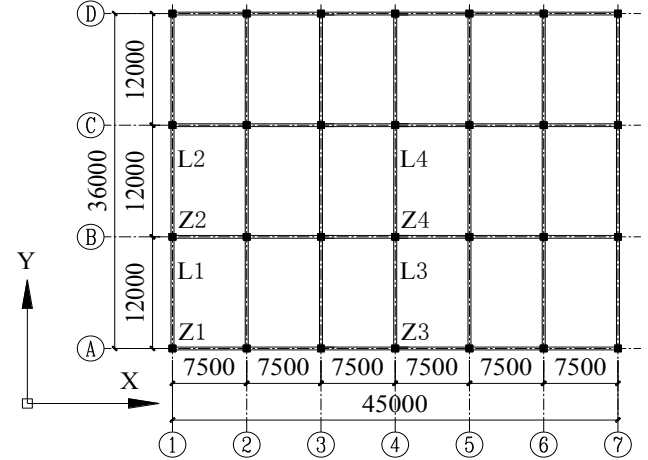

(a) Plan Layout

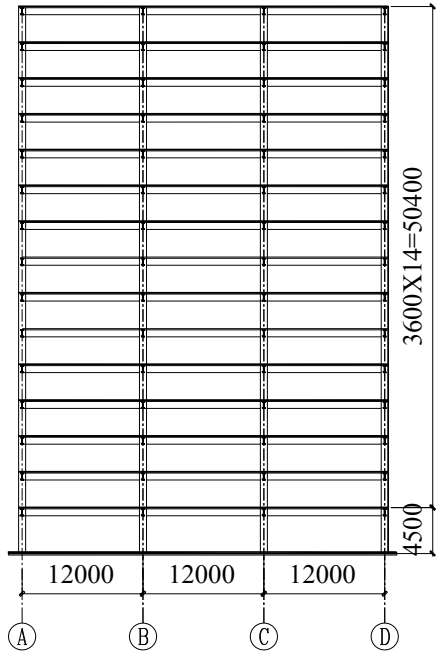

(b) Elevation Layout

Fig. 1 Plane and Elevation Layout of Frames (unit: mm)

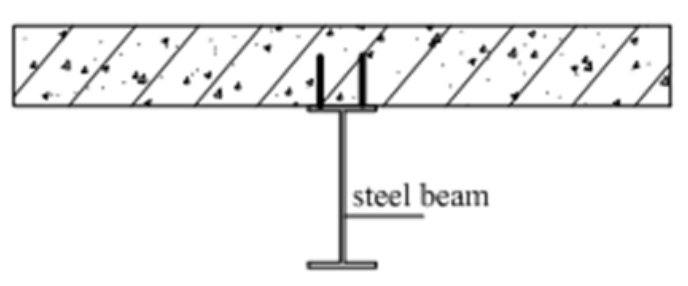

(a) Composite Beam Section

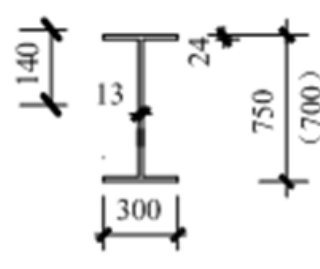

(b) Steel Beam Section

(c) CFST Column Section

Fig. 2 Sketch of Member Sections (unit: mm)

\section{Influence Analysis of Structural Elastic Aseismic Behavior}

\section{Mode Analysis}

The first five periods were shown in Table 1. And the first three modes of two frames were both translation in $\mathrm{Y}$ direction, translation in $\mathrm{X}$ direction and rotation. From the comparisons of results, the first period of the SB-CFST frame without consideration for the effect of floor slabs was larger by about $14 \%$ than that of the CB-CFST frame considering the effect of floor slabs.

Tab. 1 The First Five Periods of Frames (unit: s)

\begin{tabular}{cccccc}
\hline Mode number & 1 & 2 & 3 & 4 & 5 \\
\hline CB-CFST & 2.162 & 1.905 & 1.826 & 0.714 & 0.632 \\
SB-CFST & 2.462 & 2.085 & 2.034 & 0.808 & 0.689 \\
\hline
\end{tabular}

\section{Elastic Internal Force and Deformation Analysis}

The seismic response spectrum analysis method was applied to calculate seismic responses of structures under the horizontal earthquake. And to guarantee the computing accuracy, the first thirty modes were used. Frames were both in 8 regions of earthquake intensity category and belonged to the first seismic group. And the categorization of building site was the second kind. According to Code for seismic design of buildings [3], the earthquake affecting coefficient was 0.16 and the design 
characteristic periods was $0.35 \mathrm{~s}$, and the damping ratio of the other four structures was 0.04 . The direction of the inputting design earthquake motion was along the $\mathrm{Y}$ axis (weak direction).

The axial force and moment on earthquake action combination of column Z1 and Z4 was shown in Fig. 3. The tension was positive, and the moment in the direction of $X$ was positive. From Fig. 3, the values of axial force and moment for the two frames were close. In general, the absolute column moment value of composite beam frame was larger than that of steel beam frame, except the first, second and third storey.
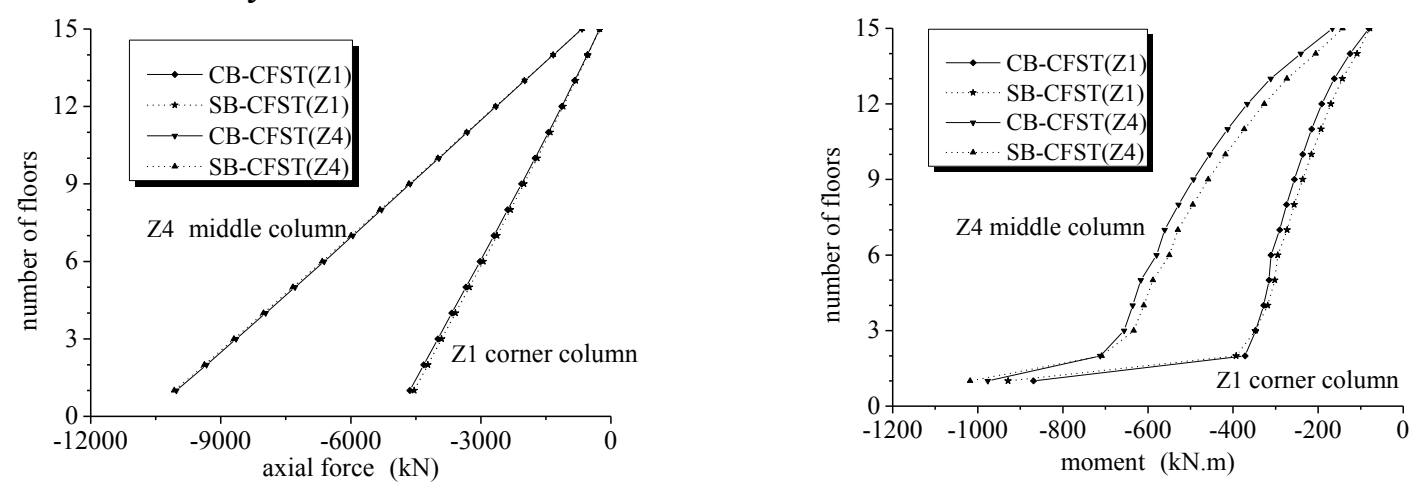

Fig. 3 Internal Force of Column Z1 \& Z4 on Earthquake Action Combination

The shear and moment on earthquake action combination of beam L1 and L4 was shown in Fig. 4 . In Fig. 4, the internal force of composite beam was larger than that of steel beam. From the statistical results, for the boundary beams the absolute shear and moment of the CB-CFST frame was larger than that of the SB-CFST frame. The absolute shear increased by about $4 \% \sim 15 \%$, and the absolute moment increased by about $5 \% \sim 18 \%$. For middle beams, the absolute shear and moment of the CB-CFST frame was larger than that of the SB-CFST frame in the mass, and the value increased was within $12 \%$.
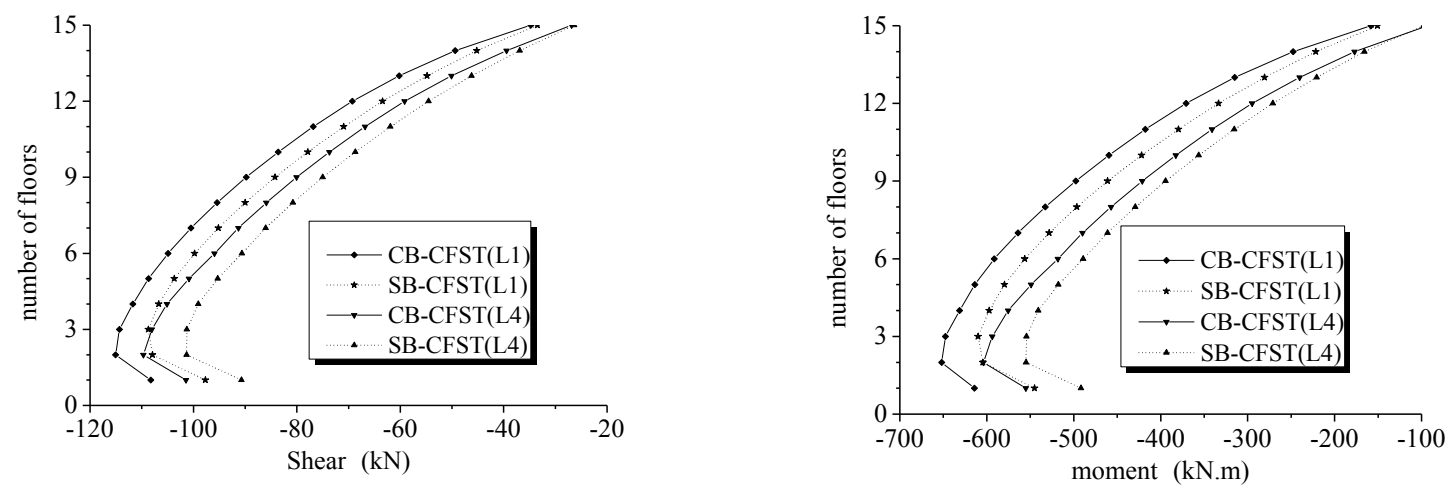

Fig. 4 Internal Force of Beam L1 \& L4 on Earthquake Action Combination
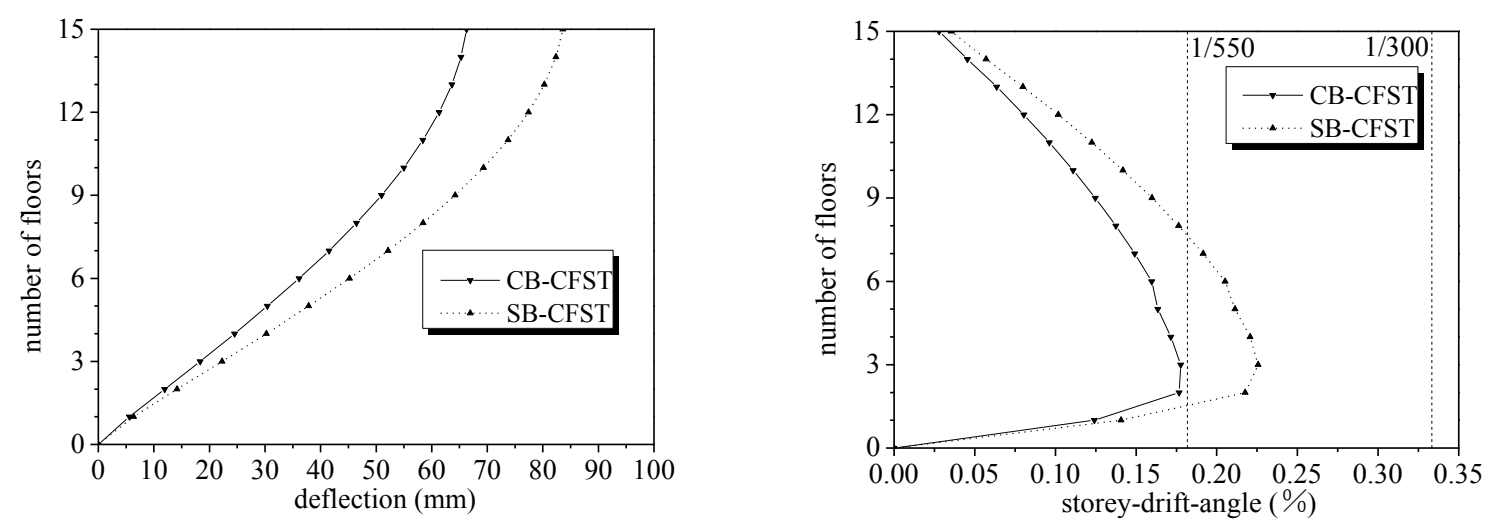

Fig. 5 Structural Deflections and Storey-drift-angle under Seismic Action in Y Direction 
The structural deflections and storey-drift-angles in every floor for the two frames were shown in Fig. 5. For the CB-CFST frame, the top storey deflection was $66.2 \mathrm{~mm}$, and the maximum storey-drift-angle in the 3rd floor was $1 / 563$. For the SB-CFST frame, the top storey deflection was $83.63 \mathrm{~mm}$, and the maximum storey-drift-angle in the $3 \mathrm{rd}$ floor was $1 / 442$. Deformations of the two frames both satisfied the demand of the storey-drift-angle limit value 1/300 in the CECS 154:2004 [4]. From the above analysis, with considering the composite effect of floor slabs, the structural integral stiffness was enhanced, while structural deformations were reduced.

\section{Elastic Time History Response Analysis under Frequent Earthquake}

El Centro wave, Kobe wave and Beijing wave was used as ground motion input for the elastic and inelastic time history analysis. The enveloping curves of storey-drift-angles under frequent earthquake for the two frames were shown in Fig. 6. From the analysis, the displacement responses for the two frames were the largest under El Centro wave, larger under Beijing wave and the smallest under Kobe wave. In general, the enveloping values of the CB-CFST frame considering the composite action of floor slabs were greater than those of the SB-CFST frame, and changed more uniformly along the height of the structure.

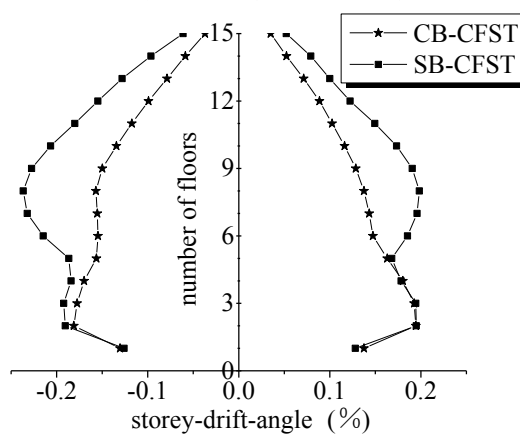

(a) El Centro Wave

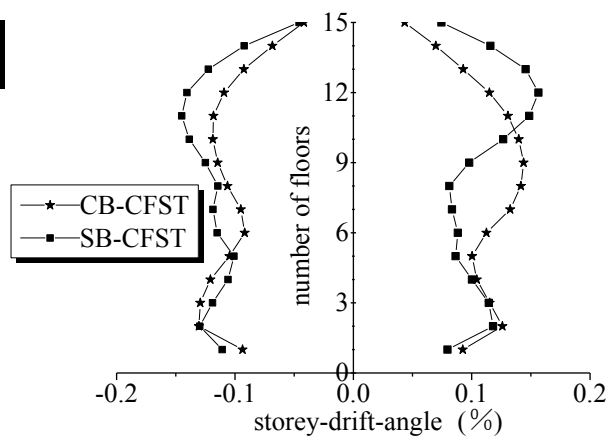

(b) Kobe Wave

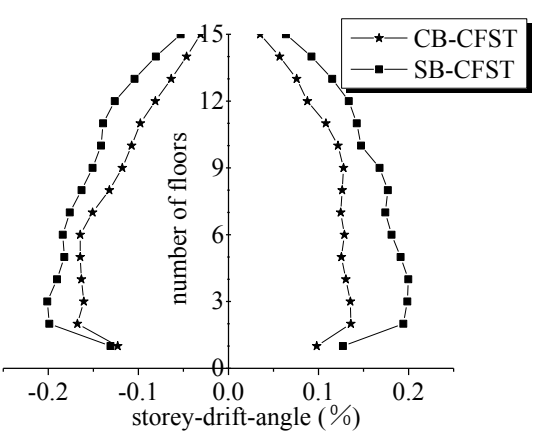

(c) Beijing Wave

Fig. 6 Enveloping Curves of the Storey-drift-angle under Low-level Earthquake

\section{Influence Analysis of the Structural Inelastic Aseismic Behavior}

To compare the deformation and damage state of two frames under rare earthquake, the elasto-plastic time history was performed for the CB-CFST frame and the SB-CFST frame. The lumped plastic model was used for nonlinear analysis. For composite beams and steel beams, bending non-linearity was considered. The Takeda plastic hysteretic model [5] was used to describe the composite beams and the Wen plastic hysteretic model[5] was used to describe the steel beams. For CFST columns, axial and bending non-linearity was considered, and the Kinematic hysteretic model [5] was adopted. The PGA of each wave was respectively scaled to $4 \mathrm{~m} / \mathrm{s}^{2}$. During the inelastic analysis, Rayleigh damping was used, and the mode damping ratio was $5 \%$.

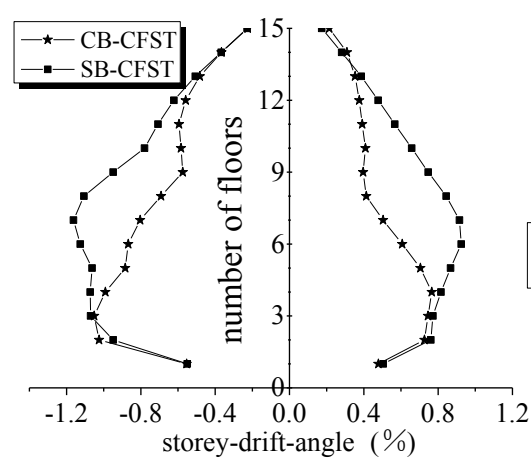

(a) El Centro Wave

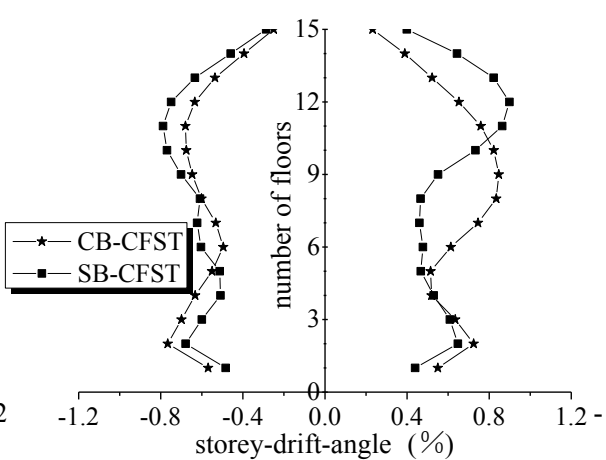

(b) Kobe Wave

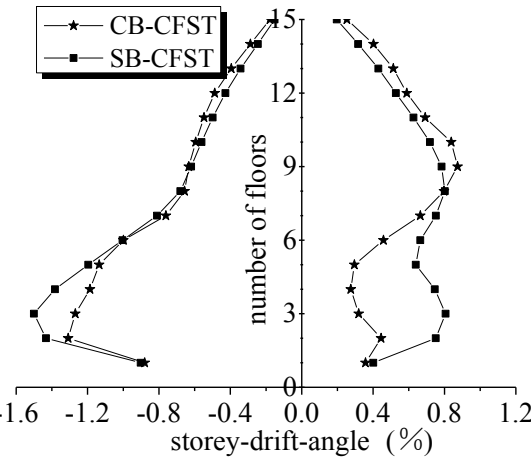

(c) Beijing Wave

Fig. 7 Enveloping Curves of the Storey-drift-angle under Rare Earthquake 


\section{Inelastic Deformation Analysis}

The enveloping curves under rare earthquake of the storey-drift-angle under three earthquake waves for the two frames were shown in Fig. 7. Compared with the results under frequent earthquake, composite action of floor slabs had less sufficient influence on the reduction of the elasto-plastic deformation. For Beijing wave, the distribution shape of the storey-drift-angles along the height of the structure under rare earthquake was slightly different from that under frequent earthquake. In the upper part of frames, the enveloping values of CB-CFST frame were larger than those of SB-CFST frame under Beijing wave. In general, the enveloping values of the CB-CFST frame considering the composite effect of floor slabs were larger than those of the SB-CFST frame, and changed more uniformly along the height of the structure.

From the computing results, values of the maximum storey-drift-angle under the action of the three earthquake waves were all satisfied the inelastic limit value $1 / 50$. The absolute values of CB-CFST frame were all smaller than those of SB-CFST frame except under the positive direction of Kobe wave. Under Kobe wave, the structural response was the smallest. Therefore, the following analysis only discussed the results of the other two waves.

To compare the structural displacement response at all time points, the top deflection history was shown in Fig. 8. In the most time, the displacement and residual deformation of the CB-CFST frame was smaller than that of the SB-CFST frame under El Centro wave. Under Beijing wave, the CB-CFST frame was smaller than that of the SB-CFST frame in the mass, while the residual deformation is larger than that of the SB-CFST frame, which could be explained from the structural damage state under rare earthquake.

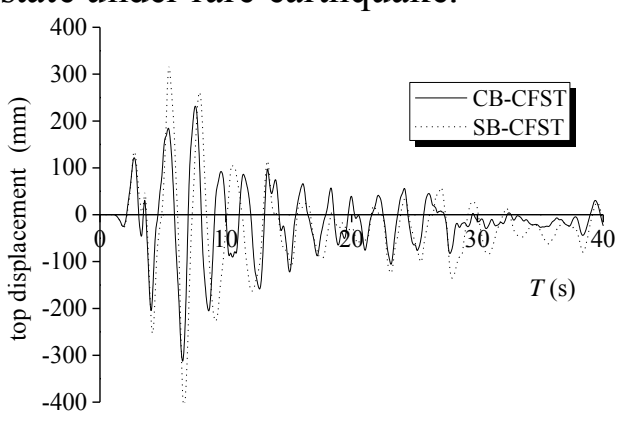

(a) El Centro Wave

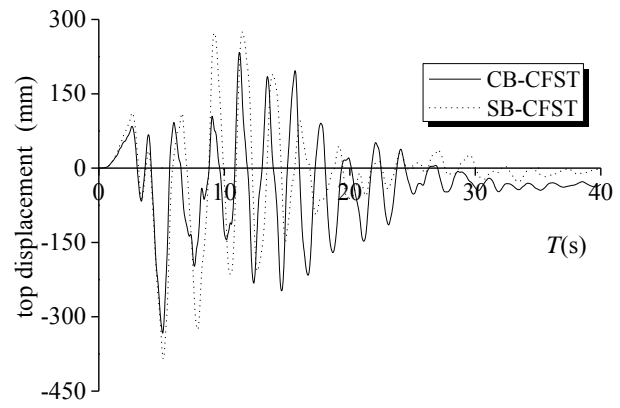

(b) Beijing Wave

Fig. 8 Inelastic Displacement Time History under Rare Earthquake
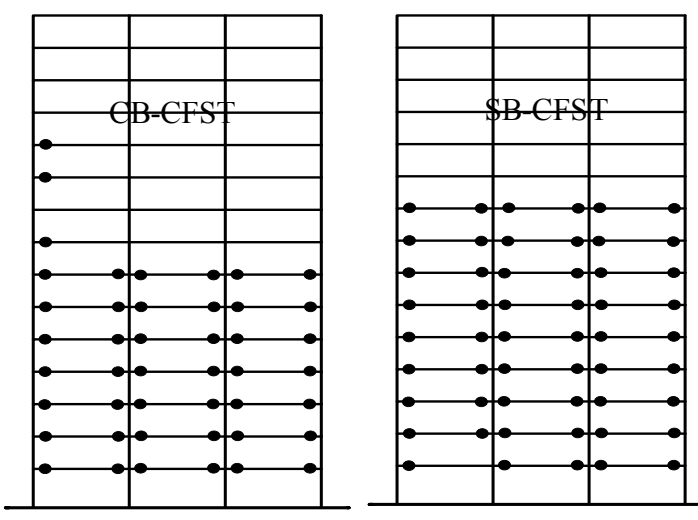

(a) El Centro Wave
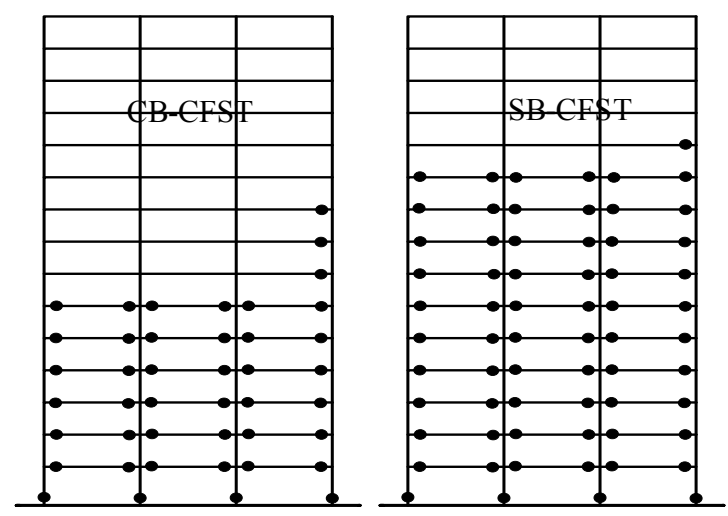

(b) Beijing Wave

Fig. 9 Distribution of Elasto-plastic Members in 4 Axis under El Centro \& Beijing Waves

\section{Structural Damage State}

The plastic hinge distributions of two frames in No. 4 axis under El Centro wave and Beijing wave were shown in Fig.9. Under El centro wave, there was no plastic hinge in the bottom of columns for 
the two frames, and the quantity of the plastic hinge of the CB-CFST frame was slightly fewer than that of the SB-CFST frame. And from the analysis results, plastic deformation of most steel beams was larger than that of composite beams. Therefore the residual deformation of the SB-CFST frame was larger than that of the CB-CFST frame. Under Beijing wave, there were plastic hinges in the bottom end of bottom columns for the two frames, and the quantity of the plastic hinge of the CB-CFST frame was more than that of the SB-CFST frame. Therefore, the residual deformation of the CB-CFST frame was larger than that of SB-CFST frame in Fig. 8(b). Because of the increased stiffness and bearing capacity of composite beams, the displacement and damage state was different, and the failure state was basically the same under the same earthquake wave. Different wave had great influence on the results. The plastic hinge distributions of the two frames were both extensive and uniform, and the failure models were both global mechanism and had the better energy-absorbing capability.

\section{Conclusions}

(1) Influence analysis of elastic aseismic behavior for mixed frames with or without considering the composite action of floor slab was carried out to compare the design internal force and deformation. Results showed that, composite action of floor slabs had great influence on the elastic dynamic behavior of frames. Without considering the composite action, the lateral stiffness was underestimated, the period and the displacement was increased, and furthermore the internal force of upper columns of the SB-CFST frame was less than that of the CB-CFST frame on earthquake action combination, which would make the structural design unsafe.

(2) Elasto-plastic dynamic time history analysis was conducted for the two frames. Results illustrated that with considering the composite action of floor slabs, the structural stiffness and bearing capacity of composite beams was enhanced, and as a whole the displacement response of the CB-CFST frame was smaller than that of the SB-CFST frame. And furthermore the storey-drift-angle changed more uniformly along the height of the building than that of the SB-CFST frame. Because of the increase of the stiffness and bearing capacity for composite beams, the linear stiffness ratio of beam to column, and the global structural stiffness and bearing capacity all changed, which would make the damage state of the two frames different. Not considering the composite action of floor slab couldn't reflect the real damage state.

\section{Acknowledgement}

This work was financially supported by the Doctor Science Research Foundation of the Education Ministry of China (20110191120032).

\section{References}

[1]Nie Jianguo, Huang Yuan, Fan Jiansheng. Experimental study on load-bearing behavior of rectangular CFST frame considering composite action of floor slab. Journal of Building Structures, 2011, 32(3): 99-108.

[2]Liu Jingbo, Liu Yangbing, Guo Bing. Seismic behavior Analysis of Steel-concrete Composite Frame Structure System. Journal of Beijing University of Technology, 2010, 36(7):934-941.

[3]Ministry of the People's Republic of China. (2010). Code for seismic design of buildings (GB 50011-2010). China Building and Industry Press, Beijing, China.

[4]CECS. (2004). Technical specification for structures with concrete-filled rectangular steel tube members (CECS 154:2004). China Planning Press, Beijing, China.

[5]Civil King Software Technology Co., Ltd (2006). China Institue of Building Standard Design \& Research. China Communications Press, Beijing. 